\title{
Predictive Capability of Existing Confinement Models for FRCM Composites Confined Concrete
}

\author{
Majid M.A. Kadhim ${ }^{1}$, Ali Hadi Adheem ${ }^{2}$, Akram Jawdhari ${ }^{3}$, Mohammed J. Altaee ${ }^{4}$ \\ \{majid.mohammed@uobabylon.edu.iq 1, inkr.ali@atu.edu.iq ${ }^{2}$, akram.hassan@uky.edu ${ }^{3}$, \\ mohammed.altaee@uobabylon.edu.iq4\} \\ ${ }^{1}$ College of Engineering, University of Babylon, Hilla, Iraq, ${ }^{2}$ Kerbala Technical Institute, Al-Furat \\ Al-Awsat Technical University, 56001 Kerbala, Iraq, ${ }^{3}$ Department of Construction and Projects, \\ University of Babylon, Hilla, Iraq. 4 Environmental Research and Studies Center, University of Babylon, \\ Hilla, Iraq.
}

\begin{abstract}
Concrete confinement by the means of external fiber reinforced polymer (FRP) jacketing has been proved to be an effective method to increase the compressive strength and ductility, as well as mitigating deterioration due to aging, chemical attacks, overloading, and seismic activity. Concerns about the organic matrices used in FRP resulted in the development of fiber-reinforced cementitious mortar (FRCM) as a costeffective and sustainable alternative system, used to repair reinforced concrete beams in shear and flexure, or in column confinement. Several theoretical models have been proposed for FRCM confined concrete elements, based on limited laboratory tests. In this study, the predictive capability of four design models has been tested by comparing their predictions for confined concrete compressive strength $\left(f_{c c}\right)$ and ultimate axial strain $\left(\varepsilon_{c c}\right)$ with a large experimental database of 137 samples found in the literature. The model developed by Ombres and Mazzuca [6] provided the highest calibrations with test data, although it still needs further improvements to include the effects of key geometric and material variables. Further efforts should be made to improve the performance of the design models and provide an accurate theoretical confinement model for FRCM-wrapped columns, for design and evaluation purposes.
\end{abstract}

Keywords: FRCM; confinement; concrete; columns; FRP; textile reinforced mortar (TRM).

\section{Introduction}

Axially loaded concrete elements may need strengthening to increase their load capacity to respond to change in function, comply with stricter design codes, address construction or design errors, and repair damage due to insufficient maintenance [1]. While column strengthening has been conventionally achieved by using steel or concrete jackets, fiber-reinforced polymer (FRP) wraps have become widely used due to favorable characteristics including high strength to weight ratio, resistance to corrosion, ease and speed of installation, and minimal change of geometry [2]. Applying FRP wraps with fibers preferably oriented in the hoop (circumferential) direction results in confining the concrete core and increasing its compressive strength and ultimate strain, thus improving ductility and energy dissipation. In regions subjected to seismic 
activities, FRP wrapping is an attractive option to provide plastic hinge regions in columns containing insufficient transverse reinforcement [3].

To respond to concerns related to the use of organic polymeric matrices, particularly their inapplicability on moist surfaces or at low temperatures, low fire resistance, lack of vapour permeability, and poor thermal compatibility, inorganic matrices have recently been used with FRP fabrics, with the system typically known as fiber-reinforced cementitious mortar (FRCM) or textile reinforced mortar (TRM) [2]. In order to increase the bond with the mortar by means of mechanical interlocking, the FRP composite is typically used in the form of an open mesh/grid configuration [4]. FRCM system has been used in many structural applications, including in flexural strengthening of reinforced concrete (RC) beams and slabs, in the shear retrofit of RC beams, and in torsion repair [5], with results showing significant increases in strength, stiffness and ductility, and reductions in crack widths and deflections [6].

In addition, FRCM system has also been used in column confinement applications utilizing plain concrete cylinders and full-scale RC columns [7, 8], with the first configuration usually used in material characterization studies and the second for examining structural effectiveness. Available studies investigated a wide range of material and geometric variables, including concrete strength, fiber type, cross-section shape (circular, rectangular), slenderness, and eccentricity of axial load [4]. It was found that the FRCM jacketing had a significant contribution to improving the strength and deformability of the tested samples.

A generic confinement model where the concrete stress-strain relation, compressive strength and ultimate strain can be defined theoretically is a fundamental entity for design and analysis as well as for analytical and numerical simulations. Several models have recently been derived for FRCM confined concrete, mainly by using available models for conventional FRP sheets and modifying for FRCM system by fitting analysis with experimental tests. In the available FRCM confinement models, the maximum strength $\left(f_{c c}\right)$ and strain $\left(\varepsilon_{c c}\right)$ of confined concrete are related by empirical formulas to analogous properties, $\left(f_{c 0}\right)$ and $\left(\varepsilon_{c o}\right)$ of un-confined concrete, and to the lateral confinement pressure $\left(f_{l}\right)$ which is a function of FRCM properties, namely its elastic modulus $\left(E_{f}\right)$, ultimate strain $\left(\varepsilon_{f u}\right)$, and a number of layers $(n)$. As these models were developed based on fitting a small set of experimental tests, in addition to noticeable differences in the mathematical formulation and variables included in each model, they are expected to yield different predictions, some of which might under or overestimate the confined concrete behavior.

The main objective of this study is to test the predictive ability of the available confinement models for FRCM system, address limitations and identify the best performing model. A large experimental database has been compiled consisting of 137 specimens having various compressive strengths, cross-section shapes, height/diameter ratios, mortar and fiber types, layer numbers, and fiber orientations. The models' predictions for $f_{c c}$ and $\varepsilon_{c c}$ were compared with experimental values, and the best performing one was identified.

\section{Experimental database}

A database of 137 specimens containing short concrete columns confined by FRCM system and tested under axial compression load was collected from literature [2-4, 9-15] and listed in Table 1,2. The database was compiled from 10 different studies and contained specimens with various material and geometric properties. When surveying the literature, only specimens reporting all material and geometric properties as well as key results values, namely $f_{c c}$ and $\varepsilon_{c c}$, 
were considered. 126 specimens were cylinders with a diameter $(D)$ ranging from 113 to 300 $\mathrm{mm}$, a height $(H)$ from 290 to $900 \mathrm{~mm}$, corresponding to an $(H / D)$ ratio from 1.9 to 3 . In these specimens, different FRP fibers were used, including 41 confined by Polyparaphenylene Benzobisoxazole (PBO) fibers (PBO-FRCM), 19 by carbon fibers (CFRCM), 30 by glass fibers (GFRCM), and 36 by basalt fibers (BFRCM). The material properties of the different fiber types are listed in Table 3 . Tests on prismatic specimens are very limited, and only 11 square columns could be located in the open literature and listed in Table 2 . These specimens were confined by either PBO, carbon, or glass fibers, and were tested under concentric load. Their dimensions ranged from 150-200 $\mathrm{mm}$ for the side of cross-section $(b, h$ in Table 2$)$ and $300-335 \mathrm{~mm}$ for the height $(H)$. Other parameters varied in the database included concrete compressive strength $\left(f_{c 0}\right)$, ranging from 15.12 to $58.06 \mathrm{MPa}$; the number of FRCM layers ( $n$ ), from 1 to 4; layer thickness $\left(t_{f}\right)$, from 0.04 to $0.25 \mathrm{~mm}$; elastic modulus of FRP $\left(E_{f}\right)$, from 52 to $270 \mathrm{GPa}$; FRP rupture strain $\left(\varepsilon_{f u}\right)$, from 1.42 to $4.75 \%$; FRP strength $\left(f_{f u}\right)$, from 1814 to $5800 \mathrm{MPa}$; and orientation of FRCM layers, from $0^{0}$ (fibers oriented circumferentially) to $90^{\circ}$ (fibers oriented longitudinally).

Table 1. Experimental database of FRCM jacketed cylindrical concrete specimens.

\begin{tabular}{|c|c|c|c|c|c|c|c|c|c|c|}
\hline Label & Reference & $D$ & $H$ & $\theta$ & $t f$ & $n$ & $f c o$ & $\varepsilon c 0 \%$ & $f c c$ & $\varepsilon c c \%$ \\
\hline CRP1-I & [6] & 152 & 290 & 90 & 0.0455 & 1 & 15.40 & 0.37 & 24.69 & 1.15 \\
\hline CRP2-I & & 152 & 290 & 90 & 0.0455 & 2 & 15.40 & 0.37 & 35.00 & 2.00 \\
\hline CRP3-I & & 152 & 290 & 90 & 0.0455 & 3 & 15.40 & 0.37 & 41.45 & 2.90 \\
\hline CRP4-I & & 152 & 290 & 90 & 0.0455 & 4 & 15.40 & 0.37 & 49.24 & 2.64 \\
\hline CRP5-I & & 152 & 290 & 45 & 0.0455 & 1 & 15.40 & 0.37 & 16.19 & 1.36 \\
\hline CRP6-I & & 152 & 290 & 45 & 0.0455 & 2 & 15.40 & 0.37 & 16.98 & 2.10 \\
\hline CRP7-I & & 152 & 290 & 45 & 0.0455 & 3 & 15.40 & 0.37 & 17.40 & 3.14 \\
\hline CRP8-I & & 152 & 290 & 30 & 0.0455 & 2 & 15.40 & 0.37 & 17.45 & 2.44 \\
\hline CRP9-I & & 152 & 290 & 30 & 0.0455 & 3 & 15.40 & 0.37 & 21.69 & 2.32 \\
\hline CRP1-II & & 153 & 294 & 90 & 0.0455 & 1 & 29.26 & 0.74 & 43.55 & 0.80 \\
\hline CRP2-II & & 153 & 292 & 90 & 0.0455 & 2 & 29.26 & 0.74 & 47.00 & 1.48 \\
\hline CRP3-II & & 153 & 292 & 90 & 0.0455 & 3 & 29.26 & 0.74 & 56.60 & 1.93 \\
\hline CRP4-II & & 153 & 295 & 90 & 0.0455 & 4 & 29.26 & 0.74 & 56.23 & 2.16 \\
\hline CRP5-II & & 152 & 290 & 45 & 0.0455 & 1 & 29.26 & 0.74 & 31.68 & 0.67 \\
\hline CRP6-II & & 152 & 290 & 45 & 0.0455 & 2 & 29.26 & 0.74 & 33.79 & 0.81 \\
\hline CRP7-II & & 152 & 290 & 45 & 0.0455 & 3 & 29.26 & 0.74 & 35.72 & 0.88 \\
\hline CRP8-II2 & & 152 & 290 & 30 & 0.0455 & 2 & 29.26 & 0.74 & 35.42 & 0.96 \\
\hline CRP9-II & & 152 & 290 & 30 & 0.0455 & 3 & 29.26 & 0.74 & 39.52 & 1.11 \\
\hline CR-1-C & [3] & 150 & 300 & 90 & 0.0455 & 1 & 58.06 & 0.54 & 54.90 & 0.56 \\
\hline CR-2-C & & 150 & 297 & 90 & 0.0455 & 2 & 58.06 & 0.54 & 51.45 & 0.63 \\
\hline CR-3-C & & 150 & 297 & 90 & 0.0455 & 3 & 58.06 & 0.54 & 55.94 & 0.52 \\
\hline CA1-2L & & 154 & 335 & 90 & 0.0455 & 2 & 24.20 & 0.13 & 30.60 & 1.16 \\
\hline CA2-2L & & 154 & 335 & 90 & 0.0455 & 2 & 24.20 & 0.13 & 31.30 & 0.68 \\
\hline CA3-2L & & 154 & 335 & 90 & 0.0455 & 2 & 24.20 & 0.13 & 31.80 & 0.31 \\
\hline CA4-3L & & 154 & 335 & 90 & 0.0455 & 3 & 24.20 & 0.13 & 33.80 & 0.96 \\
\hline CA5-3L & & 154 & 335 & 90 & 0.0455 & 3 & 24.20 & 0.13 & 36.20 & 1.14 \\
\hline CA6-3L & & 154 & 335 & 90 & 0.0455 & 3 & 24.20 & 0.13 & 39.70 & 1.49 \\
\hline CB2-2L & & 200 & 335 & 90 & 0.0455 & 2 & 24.40 & 0.19 & 30.80 & 0.22 \\
\hline CB4-2L & & 200 & 335 & 90 & 0.0455 & 2 & 24.40 & 0.19 & 33.70 & 1.27 \\
\hline CB6-2L & & 200 & 335 & 90 & 0.0455 & 2 & 24.40 & 0.19 & 29.00 & 0.17 \\
\hline CB1-3L & & 200 & 335 & 90 & 0.0455 & 3 & 24.40 & 0.19 & 34.70 & 0.92 \\
\hline CB5-3L & & 200 & 335 & 90 & 0.0455 & 3 & 24.40 & 0.19 & 32.40 & 0.24 \\
\hline
\end{tabular}


Table 1 (cont'd). Experimental database of FRCM jacketed cylindrical concrete specimens.

\begin{tabular}{|c|c|c|c|c|c|c|c|c|c|c|}
\hline Label & Reference & $D$ & $H$ & $\theta$ & tf & $n$ & fco & $\varepsilon c 0 \%$ & $f c c$ & $\varepsilon c c \%$ \\
\hline M1-1 & [13] & 113 & 300 & 90 & 0.0455 & 1 & 22.60 & 0.25 & 32.48 & 0.62 \\
\hline M1-2 & & 113 & 300 & 90 & 0.0455 & 1 & 22.60 & 0.25 & 32.66 & 0.70 \\
\hline M2-1 & & 113 & 300 & 90 & 0.0455 & 2 & 22.60 & 0.25 & 42.48 & 1.21 \\
\hline M2-2 & & 113 & 300 & 90 & 0.0455 & 2 & 22.60 & 0.25 & 42.96 & 1.14 \\
\hline M3-1 & & 113 & 300 & 90 & 0.0455 & 3 & 22.60 & 0.25 & 58.07 & 1.81 \\
\hline M3-2 & & 113 & 300 & 90 & 0.0455 & 3 & 22.60 & 0.25 & 55.80 & 1.71 \\
\hline C1-1 & [9] & 300 & 900 & 90 & 0.0455 & 1 & 22.51 & 0.11 & 30.33 & 0.17 \\
\hline C2-1 & & 300 & 900 & 90 & 0.0455 & 2 & 22.51 & 0.11 & 31.33 & 0.24 \\
\hline C3-1 & & 300 & 900 & 90 & 0.0455 & 4 & 22.51 & 0.11 & 32.50 & 0.39 \\
\hline CR-2a-C & [12] & 150 & 300 & 90 & 0.0455 & 2 & 19.52 & 0.27 & 29.63 & 0.53 \\
\hline CR-2b-C & & 150 & 300 & 90 & 0.0455 & 2 & 19.52 & 0.27 & 28.33 & 0.56 \\
\hline CR-2c-C & & 150 & 300 & 90 & 0.0455 & 2 & 19.52 & 0.27 & 22.67 & 0.70 \\
\hline CR-3a-C & & 150 & 300 & 90 & 0.0455 & 3 & 19.52 & 0.27 & 30.56 & 0.63 \\
\hline CR-3b-C & & 150 & 300 & 90 & 0.0455 & 3 & 19.52 & 0.27 & 30.84 & 1.42 \\
\hline CR-3c-C & & 150 & 300 & 90 & 0.0455 & 3 & 19.52 & 0.27 & 32.86 & 1.21 \\
\hline CR-4a-C & & 150 & 300 & 90 & 0.0455 & 4 & 19.52 & 0.27 & 33.17 & 1.21 \\
\hline CR-4b-C & & 150 & 300 & 90 & 0.0455 & 4 & 19.52 & 0.27 & 35.10 & 1.31 \\
\hline CR-4c-C & & 150 & 300 & 90 & 0.0455 & 4 & 19.52 & 0.27 & 36.96 & 1.68 \\
\hline A-MI2 & [14] & 150 & 300 & 90 & 0.0455 & 2 & 15.24 & 0.20 & 20.77 & 0.96 \\
\hline A-MII2 & & 150 & 300 & 90 & 0.0455 & 2 & 15.24 & 0.20 & 23.88 & 1.08 \\
\hline A-MI3 & & 150 & 300 & 90 & 0.0455 & 3 & 15.24 & 0.20 & 26.50 & 1.13 \\
\hline A-MII3 & & 150 & 300 & 90 & 0.0455 & 3 & 15.24 & 0.20 & 27.00 & 1.22 \\
\hline B-MII2 & & 150 & 300 & 90 & 0.0455 & 2 & 21.80 & 0.20 & 27.36 & 0.98 \\
\hline A-MII3 & & 150 & 300 & 90 & 0.0455 & 3 & 21.80 & 0.20 & 32.44 & 1.08 \\
\hline C-S2-D0 & [4] & 100 & 200 & 90 & 0.0470 & 2 & 17.90 & 0.20 & 19.20 & 0.13 \\
\hline C-S3-D0 & & 154 & 300 & 90 & 0.0470 & 2 & 16.80 & 0.16 & 22.40 & 0.33 \\
\hline C-S3-D1 & & 154 & 300 & 90 & 0.0470 & 2 & 16.80 & 0.16 & 19.50 & 0.18 \\
\hline C-S3-D2 & & 154 & 300 & 90 & 0.0470 & 2 & 16.80 & 0.16 & 16.60 & 0.25 \\
\hline G-S3-D0 & & 154 & 300 & 90 & 0.0500 & 2 & 16.80 & 0.16 & 19.30 & 0.15 \\
\hline G-S3-D1 & & 154 & 300 & 90 & 0.0500 & 2 & 16.80 & 0.16 & 14.30 & 0.16 \\
\hline G-S3-D2 & & 154 & 300 & 90 & 0.0500 & 2 & 16.80 & 0.16 & 14.20 & 0.16 \\
\hline BGP-A-1 & & 152 & 305 & 90 & 0.2460 & 2 & 20.40 & 0.24 & 29.40 & 0.95 \\
\hline BGP-A-2 & & 152 & 305 & 90 & 0.2460 & 2 & 20.40 & 0.24 & 24.30 & 0.85 \\
\hline BGP-H-1 & & 152 & 305 & 90 & 0.2460 & 2 & 20.40 & 0.24 & 30.00 & 0.83 \\
\hline BGP-H-2 & & 152 & 305 & 90 & 0.2460 & 2 & 20.40 & 0.24 & 30.00 & 0.75 \\
\hline 1B-1 & [15] & 152 & 305 & 90 & 0.2460 & 1 & 21.70 & 0.25 & 26.80 & 0.33 \\
\hline $1 \mathrm{~B}-2$ & & 152 & 305 & 90 & 0.2460 & 1 & 21.70 & 0.25 & 24.50 & 0.33 \\
\hline $1 \mathrm{~B}-3$ & & 152 & 305 & 90 & 0.2460 & 1 & 21.70 & 0.25 & 27.60 & 0.36 \\
\hline 2B-1 & & 152 & 305 & 90 & 0.2460 & 2 & 21.70 & 0.25 & 33.10 & 1.15 \\
\hline $2 \mathrm{~B}-2$ & & 152 & 305 & 90 & 0.2460 & 2 & 21.70 & 0.25 & 36.90 & 0.89 \\
\hline $2 \mathrm{~B}-3$ & & 152 & 305 & 90 & 0.2460 & 2 & 21.70 & 0.25 & 33.00 & 1.44 \\
\hline $2 \mathrm{~B}-4$ & & 152 & 305 & 90 & 0.2460 & 2 & 21.70 & 0.25 & 32.30 & 0.89 \\
\hline $2 \mathrm{~B}-5$ & & 152 & 305 & 90 & 0.2460 & 2 & 21.70 & 0.25 & 40.40 & 1.10 \\
\hline $2 \mathrm{~B}-6$ & & 152 & 305 & 90 & 0.2460 & 2 & 21.70 & 0.25 & 37.40 & 1.17 \\
\hline $2 \mathrm{U}-1$ & & 152 & 305 & 90 & 0.2460 & 2 & 21.70 & 0.25 & 35.00 & 0.40 \\
\hline $2 \mathrm{U}-2$ & & 152 & 305 & 90 & 0.2460 & 2 & 21.70 & 0.25 & 33.10 & 0.37 \\
\hline $2 \mathrm{U}-3$ & & 152 & 305 & 90 & 0.2460 & 2 & 21.70 & 0.25 & 31.50 & 0.60 \\
\hline
\end{tabular}


Table 1 (cont'd). Experimental database of FRCM jacketed cylindrical concrete specimens.

\begin{tabular}{|c|c|c|c|c|c|c|c|c|c|c|}
\hline Label & Reference & $D$ & $H$ & $\theta$ & $t f$ & $n$ & fco & $\varepsilon c o \%$ & $f c c$ & $\varepsilon c c \%$ \\
\hline $2 \mathrm{U}-4$ & [15] & 152 & 305 & 90 & 0.2460 & 2 & 21.70 & 0.25 & 39.20 & 0.96 \\
\hline $2 \mathrm{U}-5$ & & 152 & 305 & 90 & 0.2460 & 2 & 21.70 & 0.25 & 34.10 & 0.92 \\
\hline $2 \mathrm{U}-6$ & & 152 & 305 & 90 & 0.2460 & 2 & 21.70 & 0.25 & 30.70 & 0.54 \\
\hline 4B-1 & & 152 & 305 & 90 & 0.2460 & 4 & 21.70 & 0.25 & 48.60 & 0.98 \\
\hline $4 \mathrm{~B}-2$ & & 152 & 305 & 90 & 0.2460 & 4 & 21.70 & 0.25 & 47.90 & 0.98 \\
\hline 4B-3 & & 152 & 305 & 90 & 0.2460 & 4 & 21.70 & 0.25 & 47.10 & 0.98 \\
\hline S3 & [10] & 150 & 300 & 90 & 0.0460 & 2 & 15.52 & 0.23 & 22.35 & 0.32 \\
\hline S10 & & 150 & 300 & 90 & 0.0460 & 1 & 17.83 & 0.29 & 18.01 & 0.44 \\
\hline S11 & & 150 & 300 & 90 & 0.0460 & 1 & 17.83 & 0.29 & 20.15 & 0.26 \\
\hline $\mathrm{S} 12$ & & 150 & 300 & 90 & 0.0460 & 1 & 17.83 & 0.29 & 21.93 & 0.47 \\
\hline S13 & & 150 & 300 & 90 & 0.0460 & 2 & 17.83 & 0.29 & 23.00 & 0.54 \\
\hline S4 & & 150 & 300 & 90 & 0.0460 & 1 & 15.52 & 0.23 & 22.50 & 0.55 \\
\hline S5 & & 150 & 300 & 90 & 0.0460 & 2 & 15.52 & 0.23 & 22.81 & 0.62 \\
\hline S14 & & 150 & 300 & 90 & 0.0460 & 1 & 17.83 & 0.29 & 24.07 & 0.39 \\
\hline $\mathrm{S} 15$ & & 150 & 300 & 90 & 0.0460 & 1 & 17.83 & 0.29 & 26.57 & 0.44 \\
\hline S16 & & 150 & 300 & 90 & 0.0460 & 2 & 17.83 & 0.29 & 28.71 & 0.65 \\
\hline S17 & & 150 & 300 & 90 & 0.0460 & 2 & 17.83 & 0.29 & 27.99 & 0.37 \\
\hline S6 & & 150 & 300 & 90 & 0.0460 & 1 & 15.52 & 0.23 & 19.71 & 0.27 \\
\hline S7 & & 150 & 300 & 90 & 0.0460 & 2 & 15.52 & 0.23 & 22.50 & 0.71 \\
\hline S18 & & 150 & 300 & 90 & 0.0460 & 1 & 17.83 & 0.29 & 26.39 & 0.34 \\
\hline S19 & & 150 & 300 & 90 & 0.0460 & 1 & 17.83 & 0.29 & 19.43 & 0.27 \\
\hline $\mathrm{S} 20$ & & 150 & 300 & 90 & 0.0460 & 2 & 17.83 & 0.29 & 27.64 & 0.57 \\
\hline S21 & & 150 & 300 & 90 & 0.0460 & 2 & 17.83 & 0.29 & 25.85 & 0.71 \\
\hline M1-1 & [11] & 150 & 300 & 90 & 0.0865 & 1 & 21.80 & 0.41 & 25.51 & 0.51 \\
\hline M1-2 & & 150 & 300 & 90 & 0.0865 & 1 & 21.80 & 0.41 & 25.94 & 0.55 \\
\hline M1-3 & & 150 & 300 & 90 & 0.0865 & 1 & 21.80 & 0.41 & 27.47 & 0.53 \\
\hline M1-4 & & 150 & 300 & 90 & 0.0865 & 1 & 21.80 & 0.41 & 27.03 & 0.55 \\
\hline M1-5 & & 150 & 300 & 90 & 0.0865 & 1 & 21.80 & 0.41 & 24.42 & 0.55 \\
\hline M1-6 & & 150 & 300 & 90 & 0.0865 & 1 & 21.80 & 0.41 & 26.81 & 0.61 \\
\hline M2-1 & & 150 & 300 & 90 & 0.0865 & 2 & 21.80 & 0.41 & 29.21 & 0.59 \\
\hline M2-2 & & 150 & 300 & 90 & 0.0865 & 2 & 21.80 & 0.41 & 27.90 & 0.57 \\
\hline M2-3 & & 150 & 300 & 90 & 0.0865 & 2 & 21.80 & 0.41 & 26.38 & 0.62 \\
\hline M2-4 & & 150 & 300 & 90 & 0.0865 & 2 & 21.80 & 0.41 & 24.85 & 0.50 \\
\hline M2-5 & & 150 & 300 & 90 & 0.0865 & 2 & 21.80 & 0.41 & 27.25 & 0.57 \\
\hline M2-6 & & 150 & 300 & 90 & 0.0865 & 2 & 21.80 & 0.41 & 27.69 & 0.57 \\
\hline C1-1 & & 150 & 300 & 90 & 0.0865 & 1 & 21.80 & 0.41 & 29.21 & -- \\
\hline C1-2 & & 150 & 300 & 90 & 0.0865 & 1 & 21.80 & 0.41 & 27.69 & -- \\
\hline C1-3 & & 150 & 300 & 90 & 0.0865 & 1 & 21.80 & 0.41 & 29.87 & -- \\
\hline C1-4 & & 150 & 300 & 90 & 0.0865 & 1 & 21.80 & 0.41 & 28.56 & -- \\
\hline C1-5 & & 150 & 300 & 90 & 0.0865 & 1 & 21.80 & 0.41 & 28.99 & -- \\
\hline C1-6 & & 150 & 300 & 90 & 0.0865 & 1 & 21.80 & 0.41 & 27.67 & -- \\
\hline $\mathrm{C} 2-1$ & & 150 & 300 & 90 & 0.0865 & 2 & 21.80 & 0.41 & 28.34 & -- \\
\hline $\mathrm{C} 2-2$ & & 150 & 300 & 90 & 0.0865 & 2 & 21.80 & 0.41 & 27.47 & -- \\
\hline C2-3 & & 150 & 300 & 90 & 0.0865 & 2 & 21.80 & 0.41 & 27.25 & -- \\
\hline C2-4 & & 150 & 300 & 90 & 0.0865 & 2 & 21.80 & 0.41 & 30.08 & -- \\
\hline C2-5 & & 150 & 300 & 90 & 0.0865 & 2 & 21.80 & 0.41 & 28.78 & -- \\
\hline $\mathrm{C} 2-6$ & & 150 & 300 & 90 & 0.0865 & 2 & 21.80 & 0.41 & 30.74 & -- \\
\hline
\end{tabular}


Table 2. Experimental database of FRCM jacketed square concrete specimens from Colajanni et al [2] and Libreros et al [7].

\begin{tabular}{llllllllllll}
\hline Ref & Label & $b$ & $h$ & $H$ & $\theta$ & $t f$ & $n$ & $f c o$ & $\varepsilon c o \%$ & $f c c$ & $\varepsilon c c \%$ \\
\hline [3] & SB2-2L & 200 & 200 & 335 & 90 & 0.0455 & 2 & 25.5 & 0.206 & 30.1 & 0.220 \\
& SB4-2L & 200 & 200 & 335 & 90 & 0.0455 & 2 & 25.5 & 0.206 & 28.6 & 0.290 \\
& SB6-2L & 200 & 200 & 335 & 90 & 0.0455 & 2 & 25.5 & 0.206 & 26.1 & 0.380 \\
& SB1-3L & 200 & 200 & 335 & 90 & 0.0455 & 3 & 25.5 & 0.206 & 32.3 & 0.210 \\
& SB3-3L & 200 & 200 & 335 & 90 & 0.0455 & 3 & 25.5 & 0.206 & 30.2 & 0.250 \\
[4] & C-S4-D0 & 150 & 150 & 300 & 90 & 0.0470 & 2 & 17.0 & 0.131 & 20.0 & 0.136 \\
& C-S5-D0 & 150 & 150 & 300 & 90 & 0.0470 & 2 & 17.6 & 0.151 & 21.9 & 0.127 \\
& C-S6-D0 & 150 & 150 & 300 & 90 & 0.0470 & 2 & 17.9 & 0.176 & 23.5 & 0.147 \\
& G-S4-D0 & 150 & 150 & 300 & 90 & 0.0500 & 2 & 17.0 & 0.131 & 18.6 & 0.130 \\
& G-S5-D0 & 150 & 150 & 300 & 90 & 0.0500 & 2 & 17.6 & 0.151 & 18.9 & 0.185 \\
& G-S6-D0 & 150 & 150 & 300 & 90 & 0.0500 & 2 & 17.9 & 0.176 & 18.6 & 0.177 \\
\hline
\end{tabular}

Table 3. Mechanical properties of fabric used in FRCM systems.

\begin{tabular}{|c|c|c|c|c|}
\hline Type of fibers & $E_{f}(\mathrm{GPa})$ & $f_{f u} \quad(\mathrm{MPa})$ & $\varepsilon_{f u}$ & Reference \\
\hline PBO-FRCM & 270 & 5800 & 2.15 & {$[2,3,9,13]$} \\
\hline CFRCM & 225,240 & 3400 & $1.42,1.49$ & {$[5-6]$} \\
\hline GFRCM & 72 & 1440,3240 & $2.0,4.75$ & {$[2,3,9,13]$} \\
\hline BFRCM & $52-91$ & 894,1814 & $2.0,2.20$ & {$[2,3,9,13]$} \\
\hline
\end{tabular}

\section{Confinement models for FRCM}

A concrete confinement model is a theoretical formula for stress-strain behavior, and it is an essential entity in the design and analysis of axial members. Most of the confinement models for FRP and FRCM jackets contain relations similar to those presented in the Mander model for concrete confined by transverse steel reinforcement but include further modifications to account for the linear elastic nature of FRP, resulting in continuously increasing confinement effects.

This study examined the predictive capability of four confinement models available in the literature for concrete confined by FRCM system. While few other models might also exist, the four selected models received great attention and citation from the research community and therefore were selected in this study. The mathematical formulations for $\left(f_{c c}\right)$ and associated strain $\left(\varepsilon_{c c}\right)$, from either of the four models are listed in Table 4. Most of these models were developed by calibrating with a limited number of tested specimens performed by the same authors of the models, except the model Ombres [6] which was built based on a database containing the results of 152 compression tests. In all the models, $f_{c c}$ and $\varepsilon_{c c}$, are a function of the strength $\left(f_{c 0}\right)$ and associated strain $\left(\varepsilon_{c o}\right)$ of unconfined concrete, and to the lateral confining pressure $\left(f_{l u}\right.$ or $\left.f_{l, e}\right)$ which is parameter related to the volumetric confinement ratio $\left(\rho_{f}\right)$ of the external jacket and its ultimate strain and modulus, as can be seen from the following equation:

$$
f_{l u} \operatorname{orf}_{l, e}=\frac{2 E_{f} n t_{f} \varepsilon_{f u}}{D}
$$


Table 4. Confinement models for FRCM system.

\begin{tabular}{llll}
\hline $\begin{array}{l}\text { Model } \\
\text { Identification }\end{array}$ & Reference & $f_{c c} / f_{c o}$ & $\varepsilon c c / \varepsilon c o$ \\
\hline (De Caso M.) & {$[15]$} & $1+2.87\left(\frac{f_{l u}}{f_{c o}}\right)^{0.775}$ & $1+\frac{0.046}{\varepsilon_{c o}}\left(\frac{f_{l u}}{f_{c o}}\right)^{0.775}$ \\
\hline (Colajanni M.) & {$[3]$} & $2.254\left(1+7.94\left(\frac{f_{l, e}}{f_{c o}}\right)^{0.5}\right)-2\left(\frac{f_{l, e}}{f_{c o}}\right)-1.254$ & $1+5\left(\frac{f_{c c}}{f_{c o}}-1\right)$ \\
\hline (Trapko M.) & {$[13]$} & $1+2.5\left(\frac{f_{l}}{f_{c}}\right)$ & $1+10.5\left(\frac{f_{l}}{f_{c o}}\right)$ \\
\hline (Ombres M.) & {$[6]$} & $1+0.913\left(\frac{f_{l u}}{f_{c o}}\right)^{0.5}$ & $1+0.963\left(\frac{f_{l u}}{f_{c o}}\right)\left(\frac{\varepsilon_{f e}}{\varepsilon_{c o}}\right)^{0.5}$ \\
\hline
\end{tabular}

\section{Results and Discussions}

The ratio $\left(f_{c c} / f_{c o}\right)$ can be used to represent the confinement effectiveness of FRCM system by relating the compressive strength of confined concrete $\left(f_{c c}\right)$ to that of an unconfined counterpart $\left(f_{c 0}\right)$. In this section, a comparison is made between the experimentally reported $(f$ ${ }_{c c}\left(f_{c 0}\right)$ ratio and that predicted by the four models presented in Section 3. The aim of this comparison is to verify the capability of each model to predict the performance of a large, diverse, and redundant database of tested specimens.

Fig. 1 and 2 show the comparison of predicted and experimentally found $\left(f_{c c} / f_{c 0}\right)$ ratios for cylindrical and prismatic specimens, respectively. In Fig. 1 the comparisons were further divided into sub-figures based on the type of FRP mesh, namely PBO, carbon, glass and basalt. In addition, the mean and standard deviation (SD) for $\left(f_{c c} / f_{c 0}\right)$ ratios are also plotted next to the figures. It can be seen from the figures that the model proposed by Ombres and Mazzuca [6] has the best predictions for $\left(f_{c c} f f_{c 0}\right)$ ratios when compared to other models. For all FRCM systems, the mean of $\left(f_{c d} / f_{c 0}\right)$ ratios for Ombres and Mazzuca [6] model are closer to the experimental ones. The same conclusion can be made for the prismatic specimens as seen in Fig. 2. Although the model developed by Ombres and Mazzuca [6] has good performance compared to others, in some cases its predictions need more improvements which as it will be discussed later.

The models were further tested to examine whether they can capture correctly the effects of key parameters, as discussed in the next paragraphs. One of these parameters is the number of FRCM layers $(n)$ which has been studied experimentally by several researchers such as $[10$, 15]. Fig. 3 plots the experimental and model predictions of $\left(f_{c c}\right)$ versus $(n)$. It can be seen from this figure that all models were able to predict an increase in compressive strength as the number of FRCM layers increases. However, the predicted $f_{c c}$ were in most cases considerably deviating from the test value, with some models underestimating and others overestimating, as can be seen in Fig. 3. As previously mentioned, the predictions of Ombres and Mazzuca [6] model had the highest accuracy compared to others but it seems that in the case of large number of FRCM layers, the accuracy of this model decreases. The reason of this might be related to the fact that the model was developed based a limited number of specimens tested with only 4 FRCM layers. In addition, this model is generally not too sensitive to the increase of confinement effectiveness as a results of increasing the number of FRCM layers. 

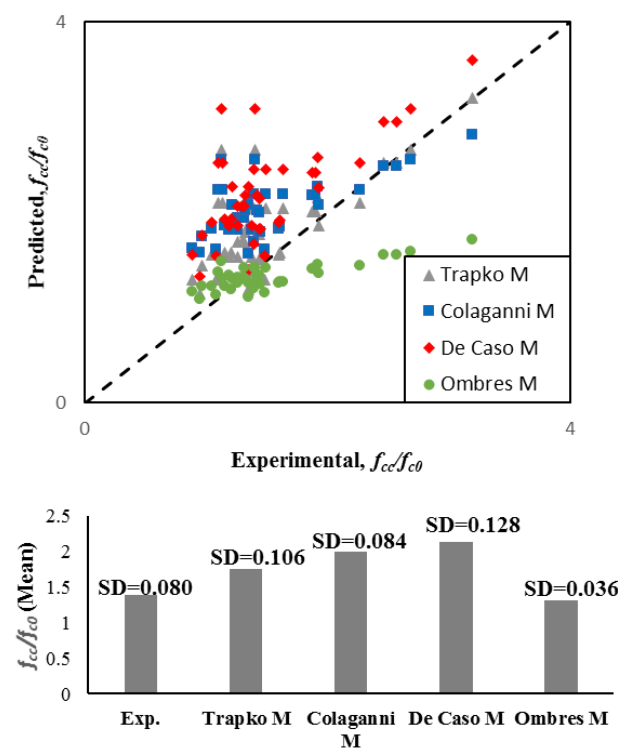

a) $\mathrm{PBO}$
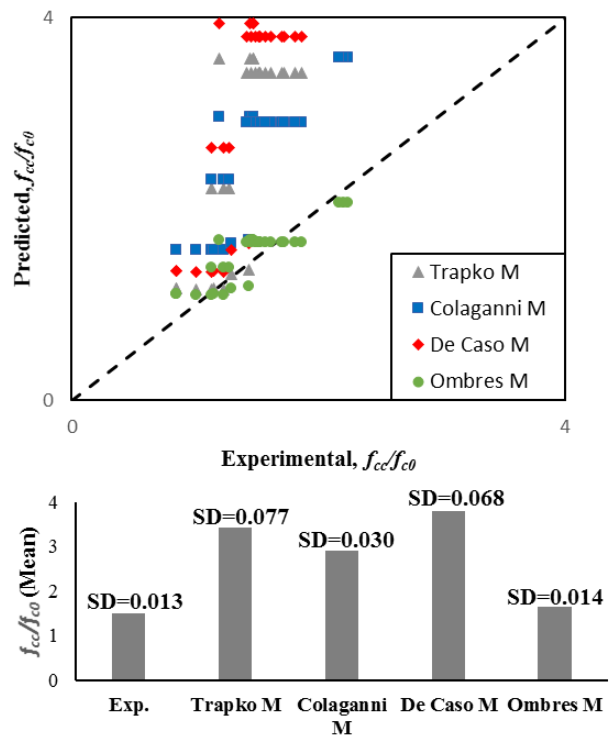

c) Glass
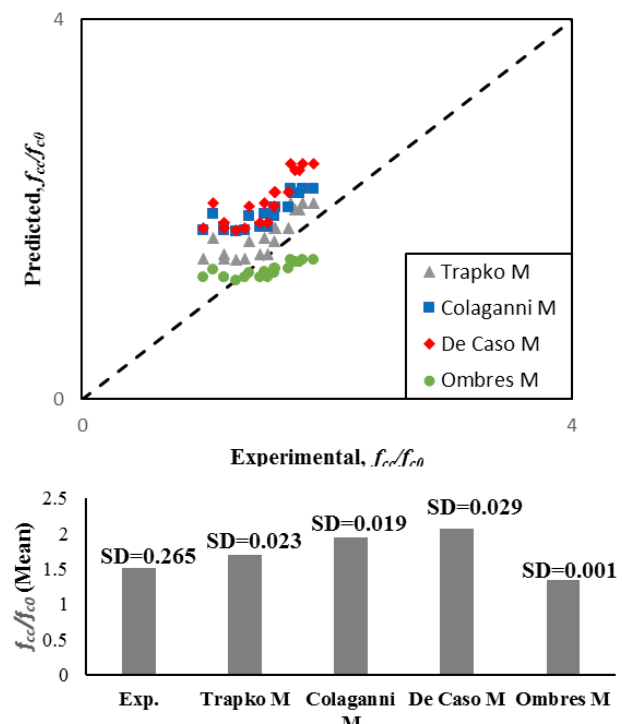

b) Carbon
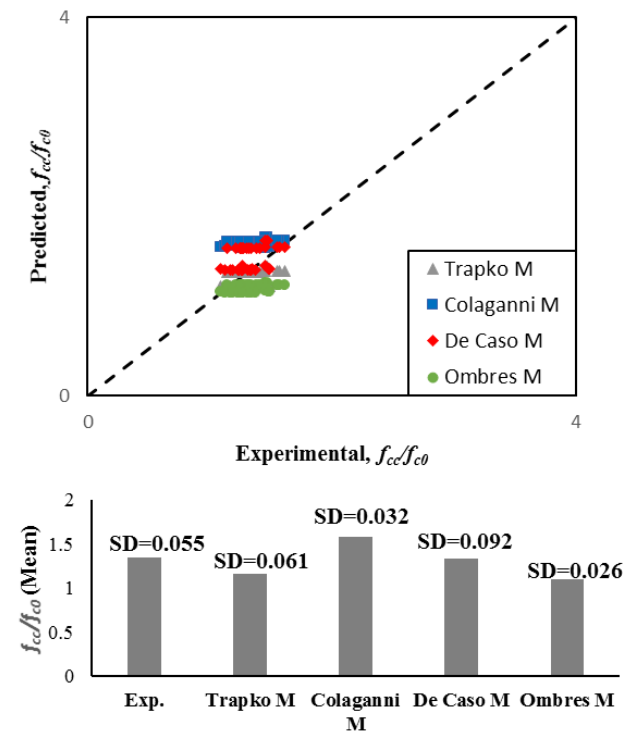

d) Basalt 
Fig. 1. Comparisons between predicted and tested confinement effectiveness $\left(\left(f_{c c} / f_{c 0}\right)\right.$ ratio) of FRCM systems for cylinder specimens.

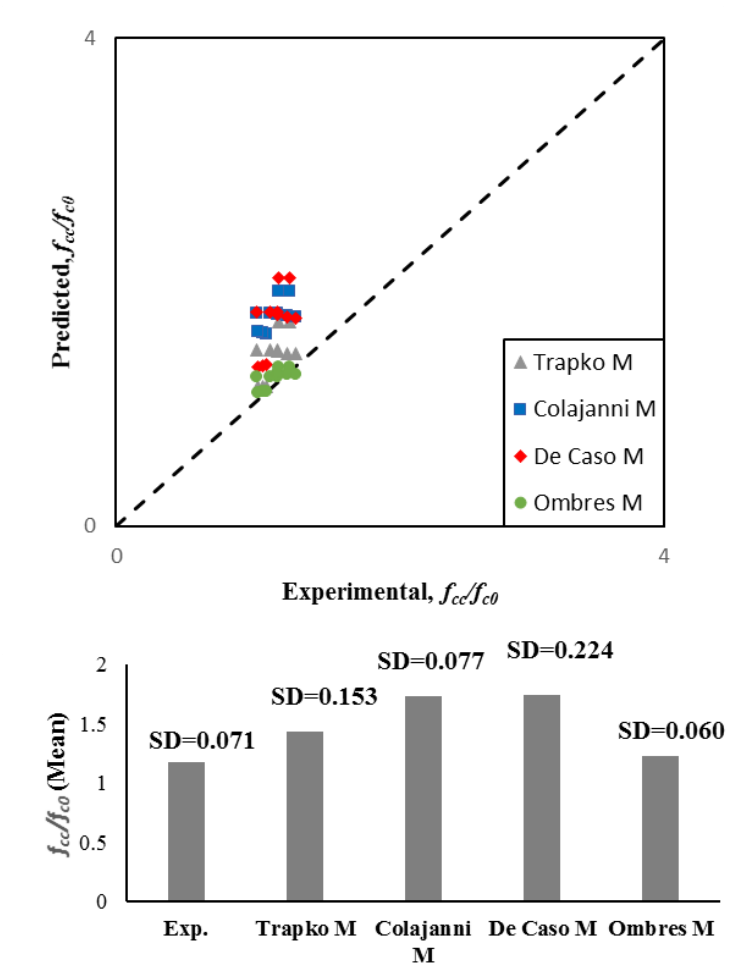

Fig. 2. Comparisons between predicted and tested confinement effectiveness $\left(\left(f_{c c} / f_{c 0}\right)\right.$ ratio) of FRCM systems for prism specimens.

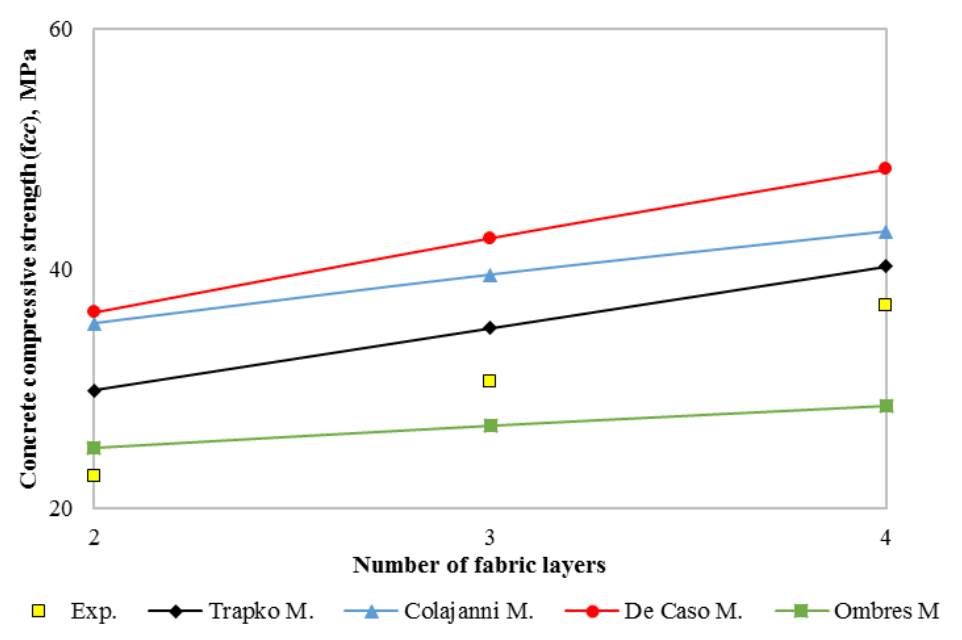


Fig. 3. Concrete compressive strength against the number of fabric layers [12].

Another important parameter is the concrete compressive strength of unconfined concrete $(f c 0)$. Ombres [2] studied the effects of $\left(f_{c 0}\right)$ experimentally and reported the resulting compressive confined strength $\left(f_{c c}\right)$. Fig. 4 plots the variation of $\left(f_{c c}\right)$ against the number of FRCM layers $(n)$ for three values of $\left(f_{c 0}\right)$, namely $15.40,29.26$ and $58.06 \mathrm{MPa}$, for each of the four, examined models. It can be noticed from Fig. 4 that the four models were able to predict the experimental values of $f_{c c}$ with a reasonable level of accuracy when $f_{c 0}$ was 15.40 and 29.26 $\mathrm{MPa}$. However, for $\left(f_{c 0}\right)$ of $58.06 \mathrm{MPa}$ (i.e. high strength concrete), predictions of Trapko, Colajanni, and De Caso models showed a large deviation from the experimental values. Predictions of Ombres and Mazzuca [6] model were closer than the other three models but were not in the same level of accuracy when compared to $\left(f_{c 0}\right)$ of 15.40 and $29.26 \mathrm{MPa}$. The deviating results for specimens with high strength concrete can be attributed to the small number of specimens tested for this class of concrete or due to the inability to of including modifications for the decrease in confinement effectiveness when the concrete strength increases, a phenomenon that has been observed from FRP-confined concrete.

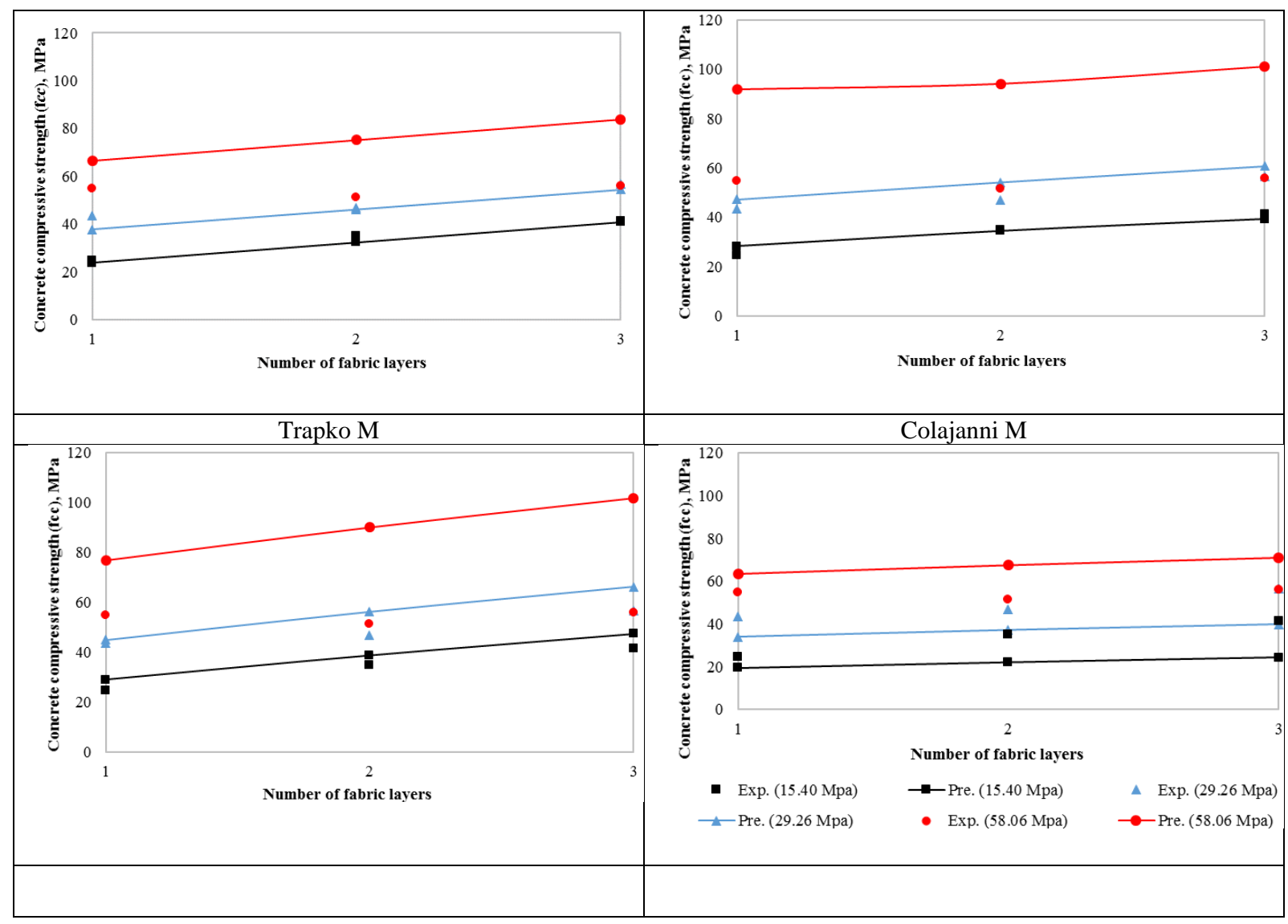


Fig. 4. Comparison between experimental and predicted $f_{c c} / f_{c 0}$ values for all models [2], with various values of concrete compressive strength $\left(f_{c 0}\right)$. 
The last variable examined in this study is the orientation of the FRP fibers $(\theta)$. The experimental results conducted by Ombres [2] confirms that the orientation of fibers has a clear effect on confinement effectiveness. However, the theoretical models apart from Ombres and Mazzuca [6] did not count for the effect of the orientation of the fibers in their formulations. Fig. 5 shows this trend and plots the variation of $\left(f_{c c}\right)$ against the number of FRCM layers $(n)$ for three values for $(\theta)$, namely 30,45 and $90^{\circ}$, for each of the four examined models. It can be seen that the models by Trapko, Colajanni, and De Caso were not able to capture the experimental behavior of FRCM jacketed concrete when the FRP fibers were not applied in the hoop direction. However, Ombres and Mazzuca [6] model were able to predict the confinement effectiveness with a reasonable agreement for $\theta=30$ and $45^{\circ}$, with some deviations in the case of longitudinally oriented fibers $\left(\theta=90^{\circ}\right)$.

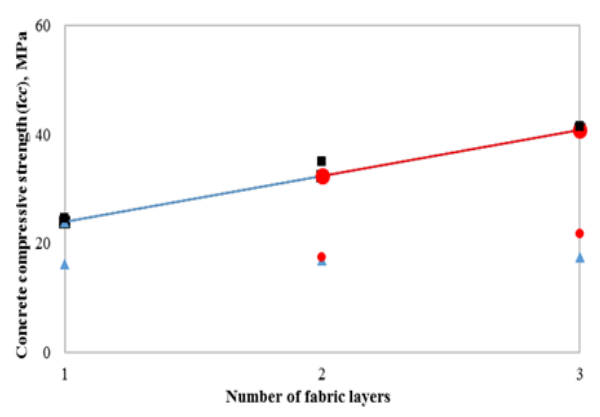

Trapko M

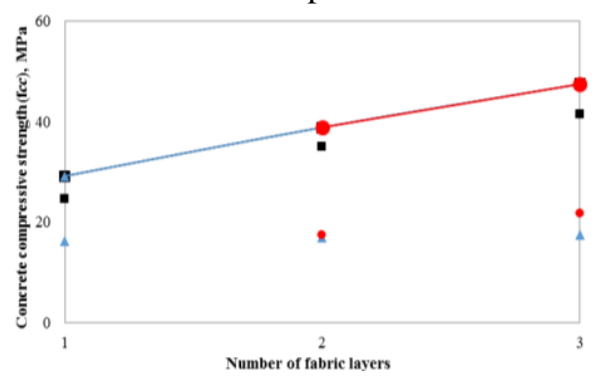

De Caso M

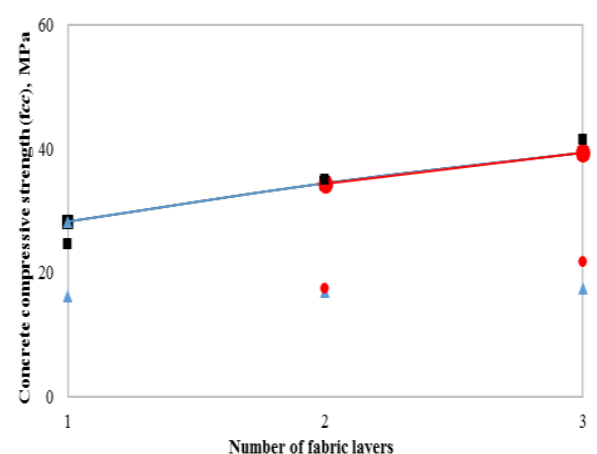

Colajanni M

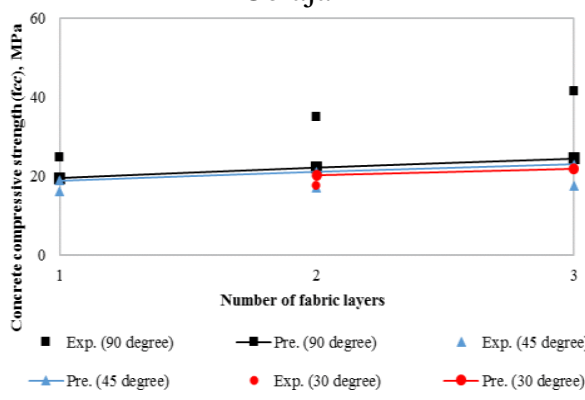

Ombres M

Fig. 5. Comparison between experimental and predicted $f_{c d} / f_{c 0}$ values for all models with various values of fibres orientation.

Based on the aforementioned discussion, it can be concluded the models examined in this study were able in many cases to predict the confinement effectiveness of FRCM jacketed concrete. However, in other instances, the models yielded under or over conservative predictions, particularly the models proposed by Trapko, Colajanni, and De Caso. The main reason for this is that these models were developed based on fitting the results of a limited number of specimens and investigated parameters conducted by the same authors presenting the model. 
Although the model by Ombres and Mazzuca [6] shown good calibrations in most cases, likely because it was derived by calibrating a large experimental database, it still need further improvements to address several drawbacks and includes key parameters such as (1) fiber orientation, number of FRCM layers (especially, more than three), properties and thickness of mortar, s specimen size, and cross-section shape.

\section{Conclusions}

This paper presented an investigational review of existing stress-strain models for concrete confined by FRCM system, an emerging technique developed to overcome limitations in FRP composites particularly those related to the use of organic matrices. Firstly, the paper compiled an experimental database containing 137 specimens of FRCM confined concrete cylinders and prisms. Variables covered in the database included the type of FRP mesh, diameter and height/diameter of circular specimens; cross-section shape examining circular and square; concrete compressive strength; thickness and number of FRCM layers, FRP elastic modulus and ultimate strength; and orientation of FRP fibers.

Four models presently available for the confinement system have been examined to check their capability of predicting the compressive strength of confined concrete $\left(f_{c c}\right)$ and associated strain $\left(\varepsilon_{c c}\right)$. Among these models, the one developed by Ombres and Mazzuca [6] provided the best predictions for the majority of experimental results. However, the model still needs further improvements to include the effects of key variables, such as fiber orientation, properties and thickness of mortar, specimen size, and cross-section shape.

\section{References}

[1] M.M. Kadhim, M.J. Altaee, A.H. Adheem, A.R. Jawdhari, A robust 3D finite element model for concrete columns confined by FRCM system, MATEC Web of Conferences, EDP Sciences, 2019, p. 01006.

[2] L. Ombres, Concrete confinement with a cement based high strength composite material, Composite Structures 109 (2014) 294-304.

[3] P. Colajanni, F. De Domenico, A. Recupero, N. Spinella, Concrete columns confined with fibre reinforced cementitious mortars: experimentation and modelling, Construction and Building Materials 52 (2014) 375-384.

[4] J. Gonzalez-Libreros, M.A. Zanini, F. Faleschini, C. Pellegrino, Confinement of lowstrength concrete with fiber reinforced cementitious matrix (FRCM) composites, Composites Part B: Engineering 177 (2019) 107407.

[5] M.Y. Alabdulhady, L.H. Sneed, C. Carloni, Torsional behavior of RC beams strengthened with PBO-FRCM composite-an experimental study, Engineering Structures 136 (2017) 393 405.

[6] L. Ombres, S. Mazzuca, Confined concrete elements with cement-based composites: confinement effectiveness and prediction models, Journal of Composites for Construction 21(3) (2017) 04016103.

[7] L. Ombres, S. Verre, Structural behaviour of fabric reinforced cementitious matrix (FRCM) strengthened concrete columns under eccentric loading, Composites Part B: Engineering 75 (2015) 235-249. 
[8] T. Trapko, Effect of eccentric compression loading on the strains of FRCM confined concrete columns, Construction and Building Materials 61 (2014) 97-105.

[9] A. D’Ambrisi, F. Focacci, G. Mantegazza, Confinamento del calcestruzzo con materiali FRCM: Analisi sperimentale e modellazione, Proc., AICAP National Symp., AICAP, Rome (in Italian) (2011).

[10] M. Di Ludovico, A. Prota, G. Manfredi, Structural upgrade using basalt fibers for concrete confinement, Journal of composites for construction 14(5) (2010) 541-552.

[11] D. García, P. Alonso, J.-T. San-José, L. Garmendia, C. Perlot, Confinement of medium strength concrete cylinders with basalt Textile Reinforced Mortar, ICPIC 2010-13th International Congress on Polymers in Concrete, 2010, pp. 1-8.

[12] L. Ombres, Confinement effectiveness in concrete strengthened with fiber reinforced cement based composite jackets, FRPCS-8. Patras, Greece (2007).

[13] T. Trapko, Confined concrete elements with PBO-FRCM composites, Construction and Building Materials 73 (2014) 332-338.

[14] T.C. Triantafillou, C.G. Papanicolaou, P. Zissimopoulos, T. Laourdekis, Concrete confinement with textile-reinforced mortar jackets, ACI Materials Journal 103(1) (2006) 28.

[15] F.J.D.C. y Basalo, F. Matta, A. Nanni, Fiber reinforced cement-based composite system for concrete confinement, Construction and Building Materials 32 (2012) 55-65. 